\title{
Rapid fabrication of ultraviolet-cured polymer microlens arrays by soft roller stamping process
}

\author{
Chih-Yuan Chang, Sen-Yeu Yang *, Ming-Hui Chu \\ Department of Mechanical Engineering, National Taiwan University, Taipei 106, Taiwan
}

Received 11 July 2006; received in revised form 6 November 2006; accepted 11 November 2006

Available online 13 December 2006

\begin{abstract}
This paper reports an innovative technique for rapid fabrication of ultraviolet-cured polymer microlens arrays based on soft roller stamping process. In this method, a soft roller with microlens array cavity is made by casting a pre-polymer of polydimethylsiloxane (PDMS) in a plastic master of microlens array. The plastic master is prepared using gas-assisted hot embossing of polycarbonate (PC) film over a silicon mold with micro-holes array. The microlens array cavity on the soft roller is filled with liquid UV curable polymer first. The roller rolls and stamps over the traveling transparent substrate. The microlens array pattern is formed. At the same time, the pattern on the substrate is cured by the UV light radiation while traveling through the rolling zone.

In this study, a roller stamping facility with UV exposure capacity has been designed, constructed and tested. The replication quality, surface roughness and optical property of the replicated microlens arrays are measured, analyzed and proved satisfactory. This study demonstrates the potential of soft roller stamping for continuous rapid mass production.
\end{abstract}

(C) 2006 Elsevier B.V. All rights reserved.

Keywords: Microlens array; Hot embossing; UV curable polymer; Roller stamping

\section{Introduction}

In recent years, polymeric microlens arrays have become important elements in many applications such as flat panel display, micro-scanning system, fiber coupling, optical data storage and optical communication etc. Many methods of fabricating microlens array have been reported. Some examples are photoresist reflow method [1,2], UV proximity printing [3], excimer laser ablation [4], gray scale photolithography [5], microjet fabrication [6], and polymer replication processes, including injection molding [7], hot embossing [8], and UV molding with electroformed metal mold [9].

Among these, injection molding and hot embossing are regarded as the best mass-production method to replicate microlens arrays. The processes can be automated and

\footnotetext{
* Corresponding author. Tel.: +8862 23625753; fax: +886283695574. E-mail address: syyang@ntu.edu.tw (S.-Y. Yang).
}

used to fabricate optical MEMS structures with high productivity. However, the processes involve high temperature and high pressure. They are time-consuming batchwise processes. To reduce heating/cooling times, UV molding with electroformed metal mold has been explored. The process uses low-viscosity UV-curable polymer and employees UV light to cure the photopolymer. This low pressure/low temperature process reduces cycle time. To further improve the productivity, we have developed a roller embossing with $\mathrm{Ni}$ mold for rapid fabrication of microlens array [10]. In this method, the thin $\mathrm{Ni}$ mold with microlens cavities is wrapped onto cylinder to form the roller. The roller is then pressing and dragging the UV-curable resin layer on the glass substrate. The microlens array pattern is formed and cured by the UV light radiation at room temperature. Although this technique is a cost-effective continuous mass-production process, the fabrication procedure of metal mold with microlens array cavity is complicated and time consuming. 
In this report, an effective soft roller stamping process with UV-curable polymer for rapid fabricating microlens arrays is proposed. The innovative technique uses a soft polydimethylsiloxane (PDMS) roller with microlens array cavity instead of a steel roller wrapped with the thin electroformed metal mold. The soft roller with microstructure cavity is directly fabricated by PDMS casting without complicated process and expensive facility. During the rolling process, the PDMS soft roller provides conformal contact with substrate and transfers UV-curable materials in the mold cavity onto the substrate. It is an effective method for rapid fabrication micro- and nano-structures on large area substrate with high productivity and low cost.

In this experiment, the thermoplastic microlens array master is first fabricated by gas-assisted hot embossing of polycarbonate (PC) film over a silicon mold with micro-holes array [11]. The PC film with microlens array is wrapped onto a silicone cylinder to form a roller with hollow shell cavity. The viscous polydimethylsiloxane (PDMS) pre-polymer solution is then poured in the hollow shell cavity of roller. After curing of the pre-polymer, the PC film can be peeled off from the PDMS material, and a soft PDMS roller with microlens array cavity is obtained. During rolling operation, the microlens array cavity on the soft roller is filled with ultraviolet-curable polymer using slit coating. Upon rolling, the soft roller is brought into contact with the transparent substrate. During rolling, the UV-curable polymer on the soft roller is stamped onto the substrate and microlens patterns are formed on it. They are cured after being exposed to UV light radiation for a period time during traveling through the rolling zone. The substrate with microlens array is thus obtained.

In this study, a soft roller stamping system with UV exposure capacity has been designed, implemented and tested. The replication quality, surface roughness and optical property of the replicated microlens arrays have been measured and analyzed.

\section{Experimental setup}

\subsection{Fabrication of the soft roller with microlens array cavity}

The fabricating processing of the soft roller with microlens array cavity is described as follows:

First of all, a silicon mold with $200 \times 200$ micro-holes array is fabricated by photolithography and deep reactive ion etching. Fig. 1 shows a SEM image and cross-sectional view of the silicon mold. The micro-holes array with a diameter of $150 \mu \mathrm{m}$, a pitch of $200 \mu \mathrm{m}$ and a depth of $60 \mu \mathrm{m}$ is measured by a surface profiler (Alpha-Step 500, TENCOR, USA).

The second step is to fabricate a microlens array master by gas-assisted hot embossing of polycarbonate (PC) film over the silicon mold with micro-holes array. As shown in Fig. 2, the $180 \mu \mathrm{m}$ thickness of PC film

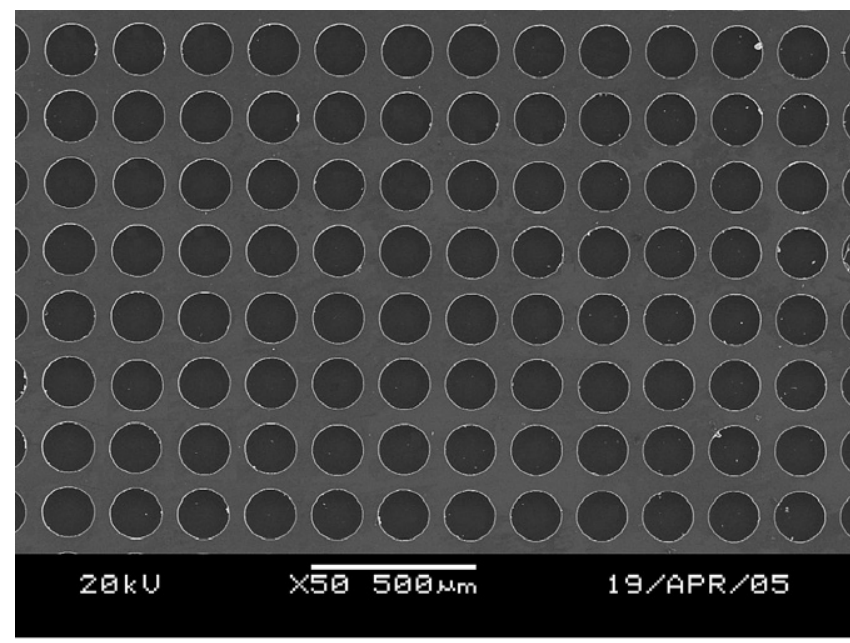

(a) Silicon mold of micro-holes array

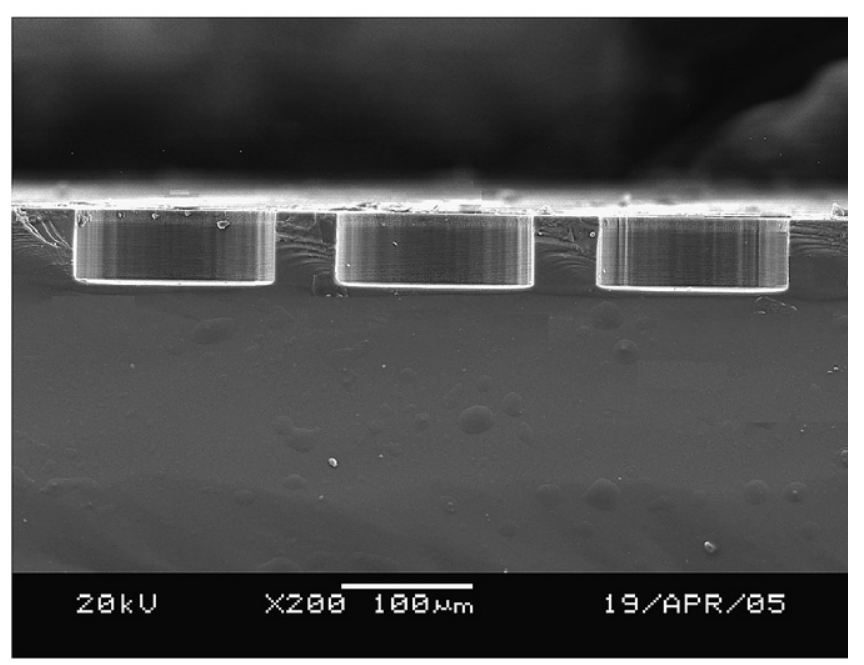

(b) Zoomed cross-section view

Fig. 1. SEM image of silicon mold with micro-holes array.

$\left(T_{\mathrm{g}} 130^{\circ} \mathrm{C}\right)$ is placed on top of the silicon mold of holes array, and the stack is placed in the closed chamber. Upon heating above the glass transition temperature of the plastic film, nitrogen gas is introduced into the chamber. Under proper gas pressure, the thermoplastic material is partially filled into the circular holes, stopped at certain distance, and formed a convex surface due to surface tension. After cooling down, the gas is vented, the chamber is opened, and the plastic film is removed from the silicon mold. PC film with microlens array can be obtained. Fig. 3 shows the SEM image and surface profile of the fabricated PC microlens array. The PC microlens array has a diameter of $150 \mu \mathrm{m}$, a pitch of $200 \mu \mathrm{m}$ and a sag height of $29.76 \mu \mathrm{m}$.

The final step is casting. As shown in Fig. 4, a PC film with microlens array is wrapped onto a silicone cylinder to form a roller with hollow shell cavity. The viscous polydimethylsiloxane (PDMS) pre-polymer 


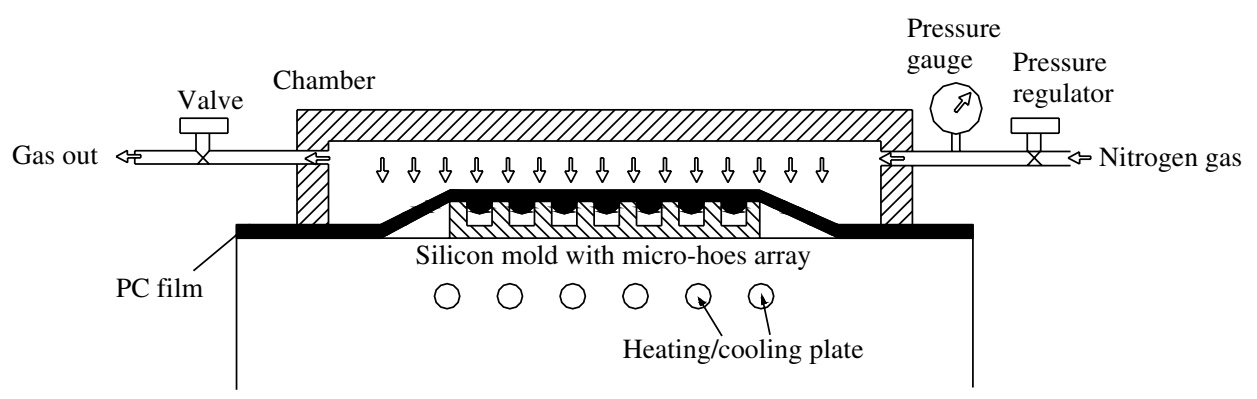

(a) Schematic drawing of gas assisted hot embossing facility and process

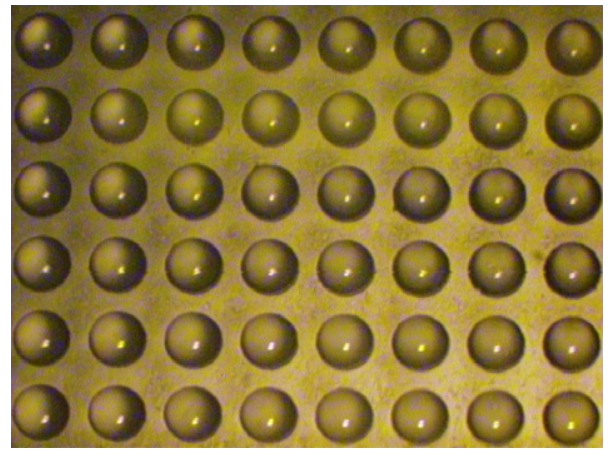

(b) CCD image of PC microlens array master

Fig. 2. Fabrication of PC microlens array master using gas-assisted hot embossing.

solution (Dow Corning SYLGARD 184) is then poured in the hollow shell cavity of roller. After curing of the pre-polymer, the PC film can be peeled off from the PDMS material. A soft PDMS roller with microlens array cavity is obtained. The microlens array cavity has a diameter of $150 \mu \mathrm{m}$, a pitch of $200 \mu \mathrm{m}$ and a depth of $29.61 \mu \mathrm{m}$.

\subsection{The soft roller stamping facility and process}

After the soft roller with microlens array cavity is obtained. A soft roller stamping is used to fabricate of polymeric microlens arrays on the transparent substrates.

Fig. 5 shows the construction of the soft roller stamping facility with UV exposure capacity. The system is composed of a UV-lamp, a transparent substrate, a soft roller stamp with microlens array cavity, a slit coating module, a movable platform and a pneumatic cylinder unit. The power of UV-lamp (Philips, UV-A365) is $400 \mathrm{~W} / \mathrm{cm}^{2}$ and wavelength is $365-410 \mathrm{~nm}$. A plate made of optical grade Polymethyl methacrylate (PMMA) is used as the substrate. The thickness of the PMMA substrate is $5 \mathrm{~mm}$. A commercial UV curable epoxy resin (Sil-more industrial company, Ltd., Taiwan) is used. The refractive index is 1.50 . The viscosity is $2500 \mathrm{cps}$ at $25^{\circ} \mathrm{C}$. A soft roller with microlens array cavity is fabricated by PDMS casting. The movable platform which holds the transparent substrates can be dragged in the direction vertical to the soft roller during rolling operation. The maximum rolling speed is $3 \mathrm{~mm} / \mathrm{s}$. The pneumatic cylinder unit provides a constant stamping pressure during the rolling process. The maximum stamping pressure is $2 \mathrm{kgf} / \mathrm{cm}^{2}$.

During the roller stamping operation, the roller rotates around the fixed axis, while the platform slides underneath the roller. The roller stamping process can be divided into three steps:

(1) The liquid epoxy resin coated onto the soft roller with microlens array cavity using slit coating process. The excess material is removed by a scraper.

(2) With a specific force is applied over the roller, the UV curable epoxy resin in the microlens array cavity of soft roller is brought into contact with the PMMA substrate.

(3) The epoxy resin is transferred onto the PMMA substrate; the microlens array is formed on the substrate after being rolled over. At the same time, these microlenses are exposed to UV radiation during moving through the rolling zone. The PMMA substrate with microlens array is obtained. 


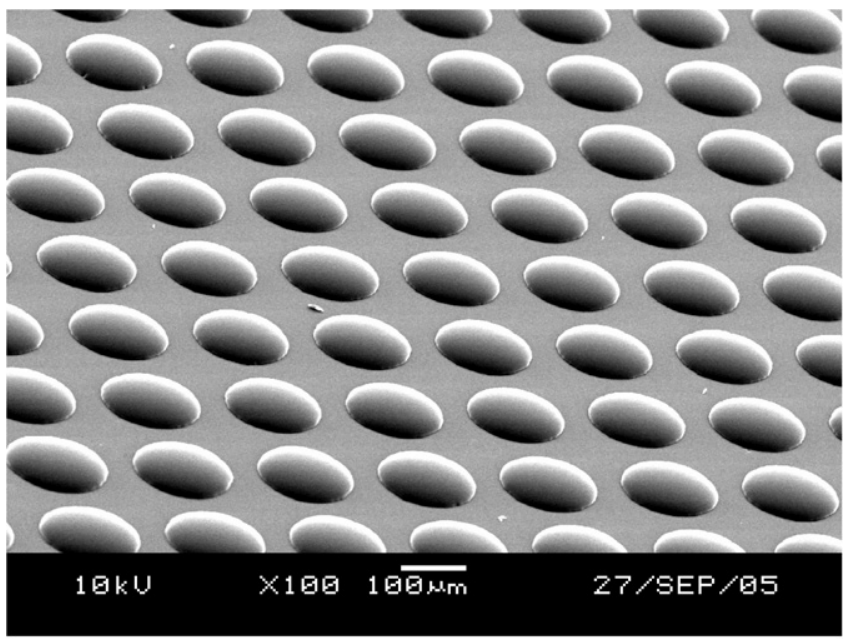

(a) SEM image of the PC microlens array

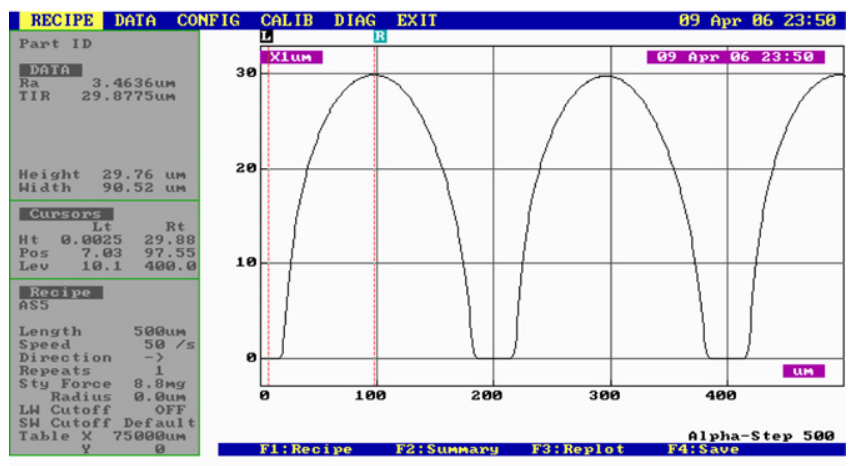

(b) Surface profile of the PC microlens array

Fig. 3. SEM image and surface profile of the PC microlens array.

\section{Results and discussion}

\subsection{Effect of process conditions on the replication quality of microlens arrays}

To study the effects of processing conditions on the replication quality of microlens, two processing parameters, i.e., the stamping pressure and rolling speed are chosen. The values of processing parameters used in the experiments and their results are shown in Table 1. The results show that the proper processing pressure is between 0.2 and $0.8 \mathrm{kgf} / \mathrm{cm}^{2}$. If the stamping pressure is too high (greater than $0.8 \mathrm{kgf} / \mathrm{cm}^{2}$ ), the excessive stamping pressure causes distortion of the patterns on the PDMS roller. As far as rolling speed is concerned, the proper rolling speed is $0.65-1.7 \mathrm{~mm} / \mathrm{s}$. When rolling speed is greater than $1.7 \mathrm{~mm} / \mathrm{s}$, the liquid photopolymer may not have enough time to adhere and to be cured on the substrate. On the contrary, if rolling speed is too low, the excessive UV intensity results in degradation and shrinkage of the patterns on the PMMA substrates.

Fig. 6 shows the SEM image and surface profile of the replicated microlens array under the condition of $0.2 \mathrm{kgf} /$ $\mathrm{cm}^{2}$ stamping pressure and $0.65 \mathrm{~mm} / \mathrm{s}$ rolling speed. Pat-

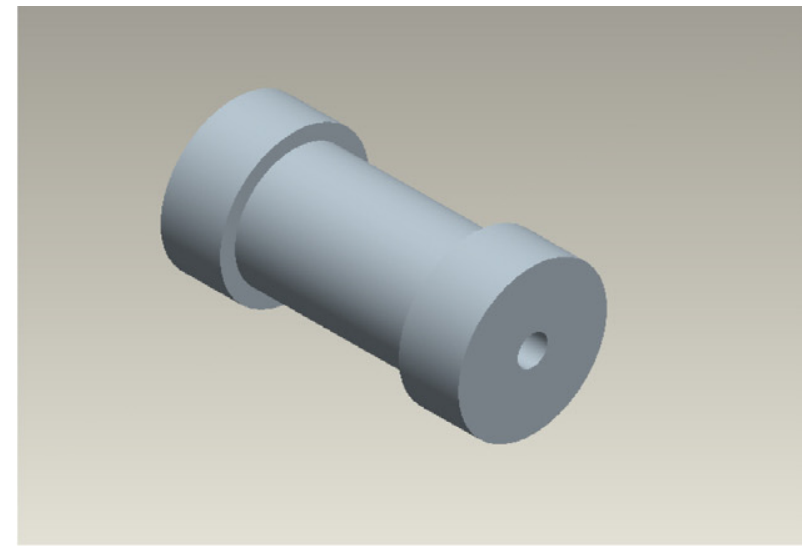

(a) Silicone cylinder without micro-features

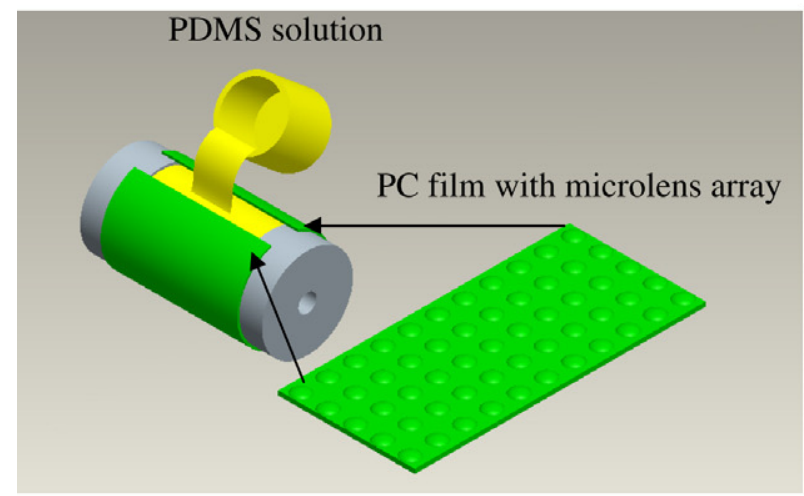

(b) PDMS casting

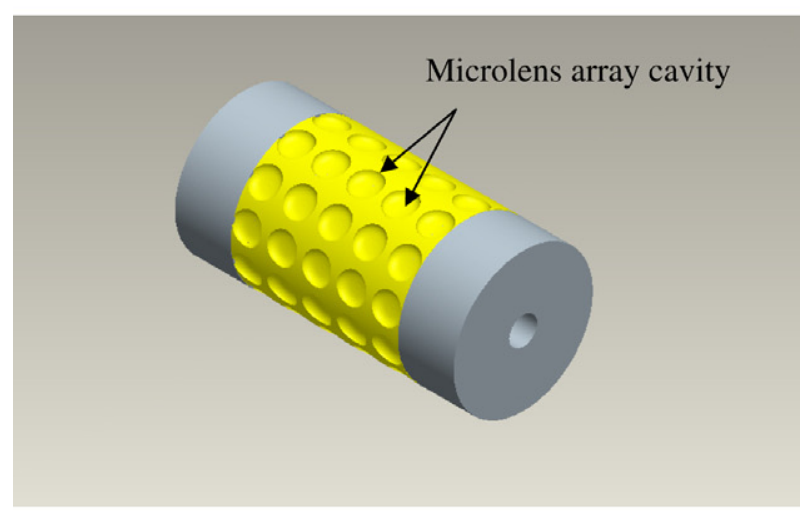

(c) Soft roller with microlens array cavity

Fig. 4. Procedures for fabricating soft roller with microlens array cavity.

terns of microlens have been successfully fabricated over the whole PMMA substrate. The epoxy microlens array has a diameter of $153 \mu \mathrm{m}$, a pitch of $200 \mu \mathrm{m}$ and a sag height of $29.55 \mu \mathrm{m}$. The deviation of the diameter and the sag height of the molded epoxy lens from the soft mold is $3 \mu \mathrm{m}(-2 \%)$ and $0.06 \mu \mathrm{m}(0.2 \%)$, respectively. In order to characterize the uniformity of the molded microlens array, the surface profiles of 50 microlenses (randomly selected in a $200 \times 200$ array of a microlens) from a single process run are measured. The average diameter is $152.3 \mu \mathrm{m}$ with a standard deviation of $0.57 \mu \mathrm{m}$. The average sag height is 


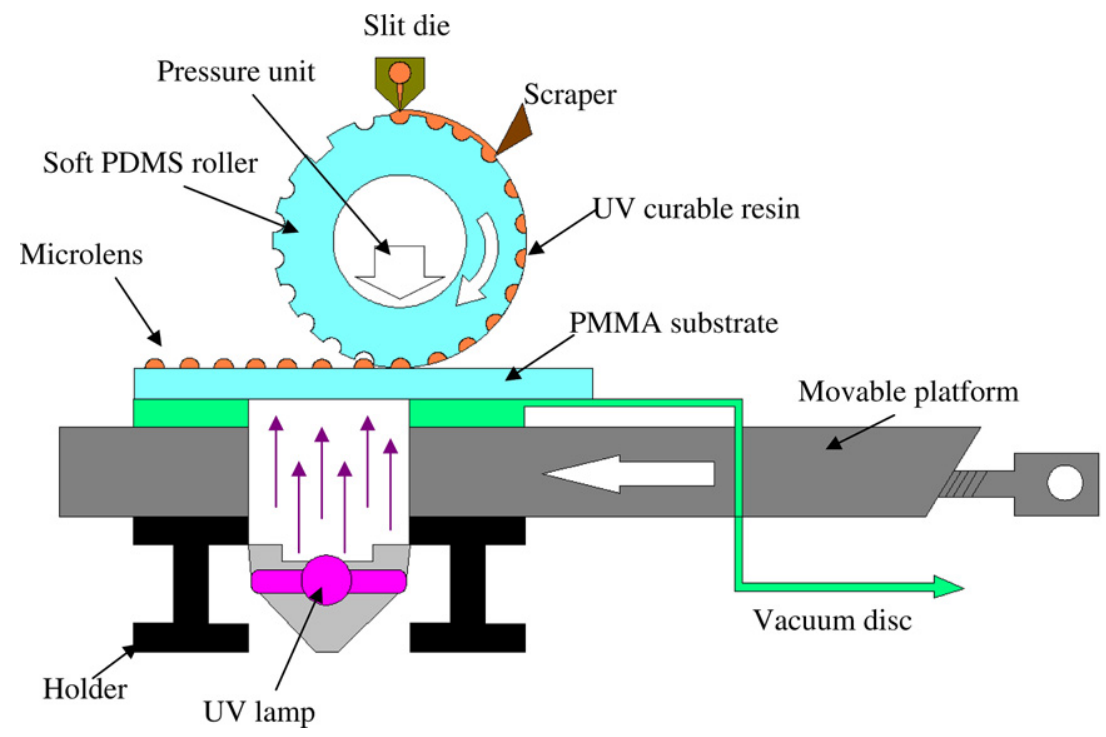

Fig. 5. Schematic drawing of the soft roller stamping facility.

Table 1

The effects of processing conditions on the replication quality of microlens

\begin{tabular}{|c|c|c|c|c|c|c|}
\hline \multirow[b]{2}{*}{ Rolling speed $(\mathrm{mm} / \mathrm{s})$} & \multicolumn{6}{|c|}{ Stamping pressure $\left(\mathrm{kgf} / \mathrm{cm}^{2}\right)$} \\
\hline & 0.1 & 0.2 & 0.4 & 0.6 & 0.8 & 1.0 \\
\hline 0.3 & $\begin{array}{l}\mathrm{ED} \%=-1.8 \\
\mathrm{EH} \%=6.15\end{array}$ & $\begin{array}{l}\mathrm{ED} \%=-1.9 \\
\mathrm{EH} \%=6.33\end{array}$ & $\begin{array}{l}\mathrm{ED} \%=-2.5 \\
\mathrm{EH} \%=6.42\end{array}$ & $\begin{array}{l}\mathrm{ED} \%=-2.2 \\
\mathrm{EH} \%=6.57\end{array}$ & $\begin{array}{l}\mathrm{ED} \%=-2.3 \\
\mathrm{EH} \%=6.62\end{array}$ & $\#$ \\
\hline 0.65 & $\begin{array}{l}\mathrm{ED} \%=-1.7 \\
\mathrm{EH} \%=5.97\end{array}$ & $\begin{array}{l}\mathrm{ED} \%=-2 \\
\mathrm{EH} \%=0.2\end{array}$ & $\begin{array}{l}\mathrm{ED} \%=-2.1 \\
\mathrm{EH} \%=0.36\end{array}$ & $\begin{array}{l}\mathrm{ED} \%=-2.1 \\
\mathrm{EH} \%=0.64\end{array}$ & $\begin{array}{l}\mathrm{ED} \%=-2.2 \\
\mathrm{EH} \%=1.3\end{array}$ & \# \\
\hline 1 & $\begin{array}{l}\mathrm{ED} \%=-1.8 \\
\mathrm{EH} \%=5.32\end{array}$ & $\begin{array}{l}\mathrm{ED} \%=-1.8 \\
\mathrm{EH} \%=0.23\end{array}$ & $\begin{array}{l}\mathrm{ED} \%=-1.9 \\
\mathrm{EH} \%=0.41\end{array}$ & $\begin{array}{l}\mathrm{ED} \%=-1.8 \\
\mathrm{EH} \%=0.65\end{array}$ & $\begin{array}{l}\mathrm{ED} \%=-2.2 \\
\mathrm{EH} \%=1.15\end{array}$ & $\#$ \\
\hline 1.35 & $\begin{array}{l}\mathrm{ED} \%=-1.6 \\
\mathrm{EH} \%=5.95\end{array}$ & $\begin{array}{l}\mathrm{ED} \%=-1.9 \\
\mathrm{EH} \%=0.21\end{array}$ & $\begin{array}{l}\mathrm{ED} \%=-1.8 \\
\mathrm{EH} \%=0.45\end{array}$ & $\begin{array}{l}\mathrm{ED} \%=-1.7 \\
\mathrm{EH} \%=0.61\end{array}$ & $\begin{array}{l}\mathrm{ED} \%=-2 \\
\mathrm{EH} \%=1.1\end{array}$ & $\#$ \\
\hline 1.70 & $\begin{array}{l}\mathrm{ED} \%=-1.9 \\
\mathrm{EH} \%=5.75\end{array}$ & $\begin{array}{l}\mathrm{ED} \%=-1.6 \\
\mathrm{EH} \%=0.15\end{array}$ & $\begin{array}{l}\mathrm{ED} \%=-1.9 \\
\mathrm{EH} \%=0.37\end{array}$ & $\begin{array}{l}\mathrm{ED} \%=-2.1 \\
\mathrm{EH} \%=0.56\end{array}$ & $\begin{array}{l}\mathrm{ED} \%=-2.2 \\
\mathrm{EH} \%=1.03\end{array}$ & $\#$ \\
\hline 2.05 & $\mathrm{X}$ & $\mathrm{X}$ & $\mathrm{X}$ & $\mathrm{X}$ & $\mathrm{X}$ & $\mathrm{X}, \#$ \\
\hline
\end{tabular}

$\mathrm{ED} \%=\left[\left(D_{\text {mold }}-D_{\text {lens }}\right) / D_{\text {mold }}\right] * 100$.

$\mathrm{EH} \%=\left[\left(H_{\text {mold }}-H_{\text {lens }}\right) / H_{\text {mold }}\right] * 100$.

$D_{\text {mold }}$ : diameter of lens cavity; $D_{\text {lens }}$ : diameter of molded lens; $H_{\text {mold }}$ : depth of lens cavity; $H_{\text {lens }}$ : height of molded lens; X: Not cured and \#: Distortion.

$29.5 \mu \mathrm{m}$ with a standard deviation of $1.79 \mu \mathrm{m}$. These results indicate good uniformity and controllability of the roller stamping molded microlenses.

\subsection{The surface roughness and optical property of replicated microlens}

To characterize the surface morphology of the ultraviolet-cured polymer microlens array, the surface roughness has been measured by atomic force microscope (AFM, Park Scientific Instruments, USA). Fig. 7 shows the AFM image and roughness analysis of a randomly picked microlens from a single lens array. The average surface roughness $\left(R_{\mathrm{a}}\right)$ of a microlens was $8.23 \mathrm{~nm}$ over a $5 \mu \mathrm{m} \times 5 \mu \mathrm{m}$ area on the microlens top surface.

The optical property of the replicated microlens array is further measured using a beam profiler. The beam profiler is composed of expanding lenses, a filter, a micrometer scale resolution Z-stage, a microscope, a CCD system and a $633 \mathrm{~nm}$ laser light source. The average focal length is measured to be $233 \mu \mathrm{m}$ for the formed epoxy lens with a diameter of $153 \mu \mathrm{m}$ and a sag height of $29.55 \mu \mathrm{m}$. Fig. 8 shows a portion of the spot patterns and two-dimensional focus intensity distribution produced by an epoxy microlens array. The images reveal that the pitch and the intensity of the focused light spots are uniform. 


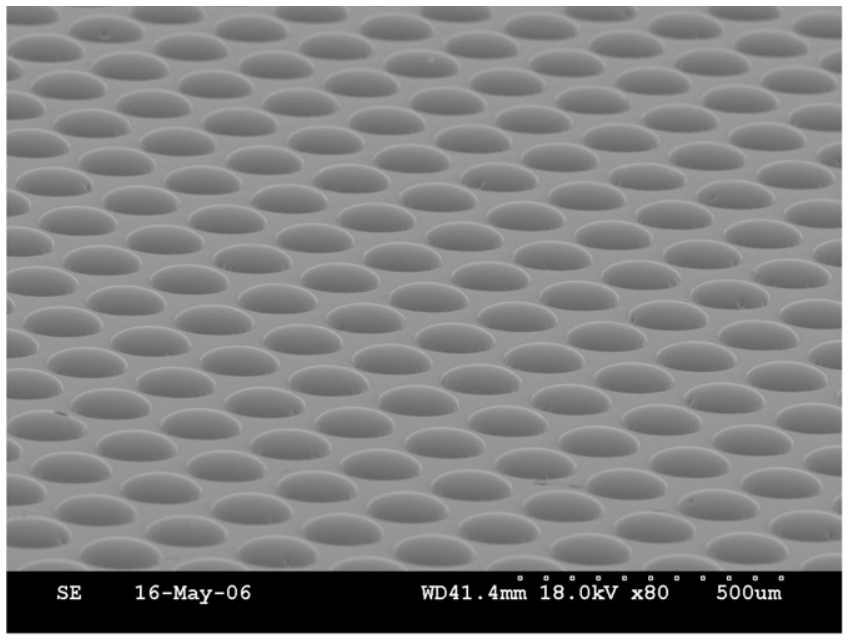

(a) SEM image of the epoxy microlens array

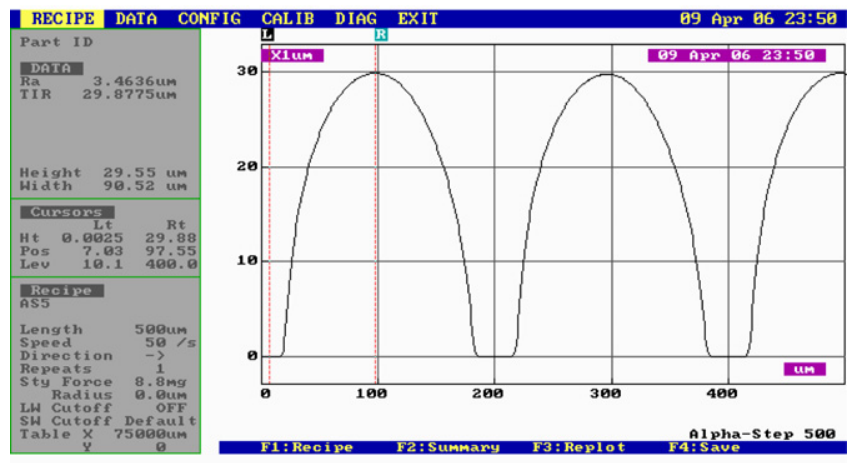

(b) Surface profile of the epoxy microlens array

Fig. 6. SEM image and surface profile of the replicated epoxy microlens array.

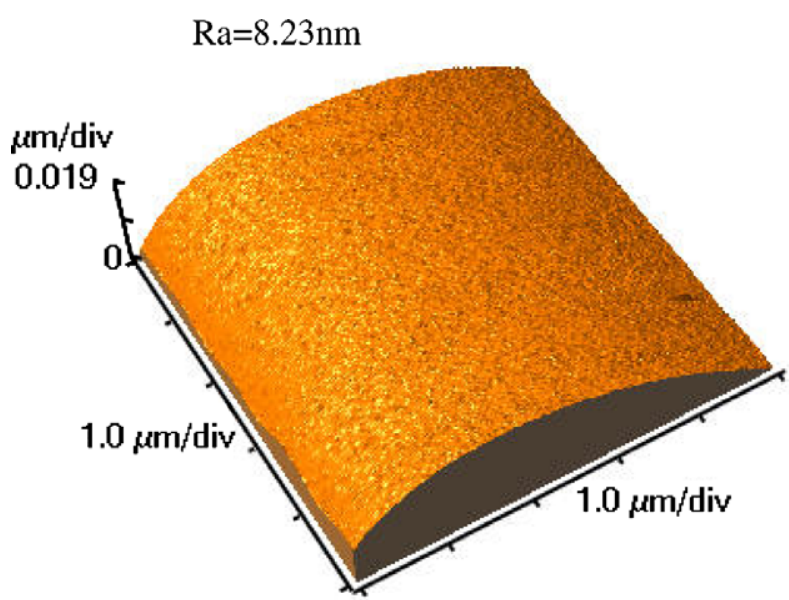

Fig. 7. AFM image and surface roughness of an epoxy microlens.

\section{Conclusions}

In this paper, an innovative method for fabricating microlens array on PMMA substrates using soft roller stamping process is reported. A soft roller stamping facil-

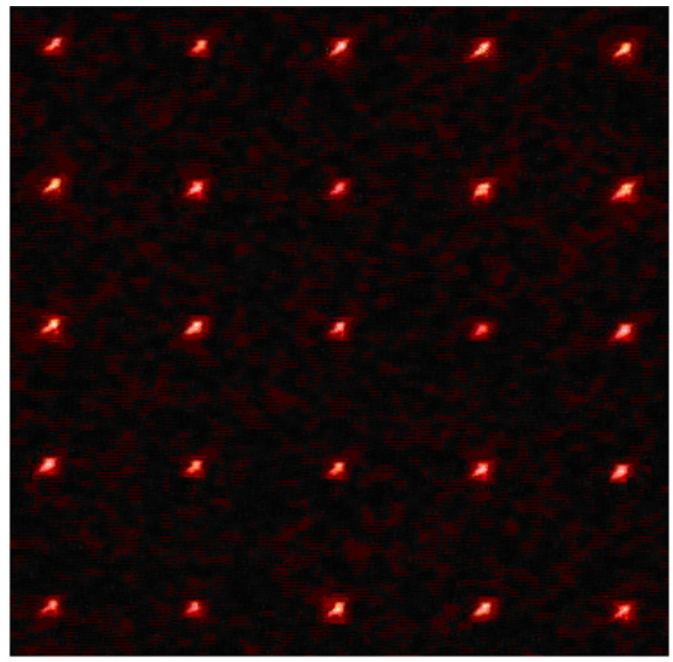

(a) Light spots pattern of an epoxy microlens array

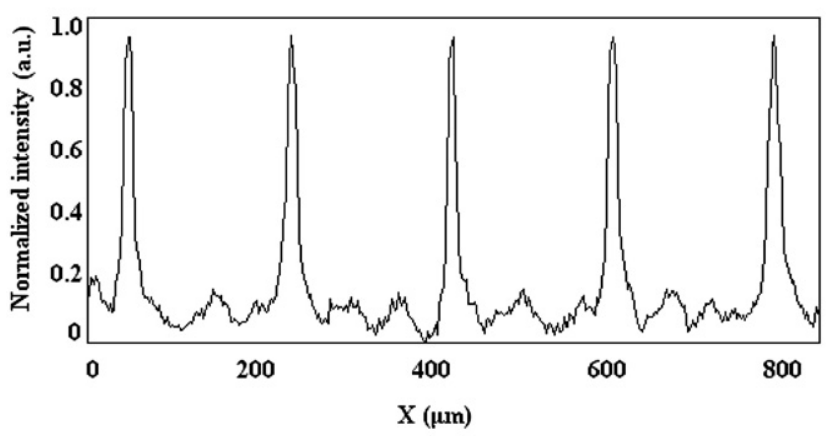

(b) Normalized intensity distribution of an epoxy microlens array

Fig. 8. Light spots pattern and intensity profile of an epoxy microlens array.

ity with UV exposure capacity has been implemented and tested. Under the proper processing conditions, a large arrays of $200 \times 200$ epoxy microlens with a lens diameter of $153 \mu \mathrm{m}$, a pitch of $200 \mu \mathrm{m}$ and a sag height of $29.55 \mu \mathrm{m}$ has been successfully fabricated. The measured surface roughness of the microlens is $8.23 \mathrm{~nm}$. The pitch and intensity distribution of the micorlens array are uniform. These results show the potential of the soft roller stamping process for mass production of microlens arrays with high productivity and low cost. In addition, this effective technology can even be developed to a roll to roll process for fabrication of other micro- and nanooptical components.

\section{Acknowledgement}

This work was partially supported by the National Science Council (series no NSC94-2212-E-002-036) of Taiwan. The experimental work is mainly carried out at the MEMS Laboratory in the Nano-Electro-Mechanical-Systems Research Center at NTU. The financial and technique supports are gratefully acknowledged. 


\section{References}

[1] D. Daly, R.F. Stevens, M.C. Hutley, N. Davles, Meas. Sci. Technol 1 (1990) 759-766.

[2] C.P. Lin, H. Yang, C.K. Chao, J. Micromech. Microeng. 13 (2003) $775-781$.

[3] C.P. Lin, H. Yang, C.K. Chao, J. Micromech. Microeng. 13 (2003) 748-757.

[4] S. Mihailov, S. Lazare, Appl. Opt. 32 (1993) 6211-6218.

[5] K. Totsu, M. Esashi, J. Vac. Sci. Technol. B 23 (2005) 1487-1490.
[6] D.L. MacFarlane, V. Narayan, J.A. Tatum, W.R. Cox, T. Chen, D.J. Hayes, IEEE Photonics Technol. Lett. 6 (1994) 1112-1114.

[7] B.K. Lee, D.S. Kim, T.H. Kwon, Microsyst. Technol. 10 (2004) 531535.

[8] N.S. Ong, Y.H. Koh, Y.Q. Fu, Microelectron. Eng. 60 (2002) 365-379.

[9] S.-M. Kim, S. Kang, J. Phys. D: Appl. Phys. 36 (2003) 2451-2456.

[10] C.Y. Chang, S.Y. Yang, J.L. Sheh, Microsyst. Technol. 12 (2006) 754-759.

[11] C.Y. Chang, S.Y. Yang, L.S. Huang, J.H. Chang, Infrared Phys. Technol. 48 (2006) 163-173. 